\title{
Intra-uterine environment influences glomerular number and the acute renal adaptation to experimental diabetes
}

\author{
S. E. Jones ${ }^{1}$, R. W. Bilous ${ }^{1}$, A. Flyvbjerg ${ }^{2}$, S. M. Marshall ${ }^{1}$ \\ ${ }^{1}$ School of Clinical Medical Sciences, University of Newcastle upon Tyne. UK \\ ${ }^{2}$ Department of Diabetes and Endocrinology, Aarhus Kommunehospital, Aarhus, Denmark
}

\section{Abstract}

Aims/hypothesis. We sought to test the hypothesis of whether low birth weight rats would have reduced glomerular number, higher systolic blood pressure and an altered acute response to streptozotocin diabetes compared to normal birth weight rats.

Methods. Female offspring of Wistar rats fed an isocaloric diet containing either $6 \%$ casein (LPD) or $18 \%$ casein (NPD) in utero were studied. Birth weight, body weight, systolic blood pressure and urine albumin excretion were measured before and after streptozotocin diabetes. Glomerular number and volume were estimated after one week of diabetes.

Results. The LPD rats were of low birth weight $(5.4 \pm 0.5 \mathrm{~g}$ vs $6.4 \pm 0.8 \mathrm{~g}, p<0.0001)$ with higher systolic blood pressure $(137 \pm 9 \mathrm{mmHg}$ vs $120 \pm$ $7 \mathrm{mmHg}, p<0.0001)$ and reduced glomerular number $(17435 \pm 2074$ vs $24846 \pm 1864, p<0.0001)$. The
LPD rats had smaller kidneys $(0.925 \pm 0.009 \mathrm{~g}$ vs $1.200 \pm 0.173 \mathrm{~g}, p=0.041$ ) but similar glomerular volume to NPD control rats $\left(1.11 \pm 0.15 \cdot 10^{6} \mu \mathrm{m}^{3}\right.$ vs $1.08 \pm 0.17 \cdot 10^{6} \mu^{3}$ ). After 1 week of diabetes LPD rats had a greater proportional increase in renal size (diabetes $50 \pm 12 \%$ vs control $20 \pm 4 \%, p=0.003$ ). Insulin suppressed renal hypertrophy in both LPD and NPD rats but failed to suppress glomerular hypertrophy in LPD rats $\left(1.48 \pm 0.21 \cdot 10^{6} \mu \mathrm{m}^{3}\right.$ vs $\left.1.03 \pm 0.23 \cdot 10^{6} \mu \mathrm{m}^{3} p=0.015\right)$.

Conclusion/interpretation. Abnormal intra-uterine environment reduces both renal size and glomerular number and influences the acute renal adaptation to experimental diabetes. [Diabetologia (2001) 44: 721728]

Keywords Intra-uterine environment, glomerular number, glomerular volume, diabetic nephropathy.
The possibility that intra-uterine environment influences the development of chronic diseases such as hypertension and diabetes in adulthood forms the basis of the 'fetal origins hypothesis' [1-3]. One proposed mechanism for the development of hypertension in

Received: 25 September 2000 and in revised form: 26 February 2001

Corresponding author: Dr Sue Jones, School of Clinical Medical Sciences, The Medical School, Framlington Place, Newcastle upon Tyne, NE2 4HH, UK

Abbreviations: LBW, low birth weight; NBW, normal birth weight; LPD, low protein diet; NPD, normal protein diet; UAE, urine albumin excretion; SBP, systolic blood pressure; Cont, control group; Diab, diabetes group; D + I, diabetes plus insulin group. subjects exposed to abnormal intra-uterine environment is by a reduction in glomerular number $[4,5]$.

In both human and experimental diabetes, changes in glomeruli are apparent at an early stage and rising blood pressure drives the progression of diabetic nephropathy. At diagnosis of diabetes, glomerular filtration rate increases and renal hypertrophy is observed [6, 7]. It is believed that persistence of renal hypertrophy and hyperfiltration despite good blood glucose control could predispose an individual to develop diabetic nephropathy [8]. In the streptozotocin rat model of diabetes renal enlargement with glomerular hypertrophy and hyperfiltration are apparent within seven days of induction of experimental diabetes [9-11].

It is possible that a person exposed to an abnormal intra-uterine environment could, due to a reduction 
in filtration surface area from reduced glomerular number, show abnormal initial renal response to acute diabetes. This abnormal response could subsequently influence the future development of diabetic nephropathy.

Retrospective studies in humans have attempted to address whether low birth weight (LBW), a marker of abnormal intra-uterine nutrition, is associated with increased risk of nephropathy. These studies have produced conflicting results $[12,13]$. Using animal models of LBW and diabetes it is possible to prospectively investigate whether abnormal intra-uterine environment can influence the acute renal adaptation to diabetes.

Animal models of LBW include intra-uterine administration of gentamicin, unilateral uterine artery ligation $[14,15]$ and protein energy malnutrition [16-18]. Such models are associated with high intrauterine and early neonatal losses and as such they could be too extreme to be relevant to the human situation. A less extreme model is the use of intra-uterine low protein diet which is isocaloric to standard rat chow. Low protein diet (LPD) treatment in utero results in LBW offspring that have raised systolic blood pressure (SBP) [19, 20] and reduced glomerular number [15, 20, 21].

To date no study has specifically examined the acute renal response to diabetes in rats exposed LPD in utero. Using this animal model of intra-uterine LPD to produce LBW rats and by inducing diabetes at 12 weeks of age using streptozotocin, we sought to test the hypothesis that LPD rats with increased systolic blood pressure, reduced renal size and reduced glomerular number would have an altered acute response to experimental diabetes.

\section{Subjects and methods}

Animal husbandry. All animal experiments were done in accordance with the 1986 United Kingdom Home Office Regulations.

Virgin Wistar female rats (Charles River, Kent, UK) received either $6 \%$ casein diet (LPD) or $18 \%$ casein diet (NPD) for one week before timed-mating and for the duration of their pregnancy. The diets were isocaloric and produced by Usine d'Alimenatation Laboratories, France. The source of protein, carbohydrate and lipid in each diet was identical and the LPD contained supplemental methionine to prevent essential amino acid deficiency ( $0.3 \%$ vs $0.23 \%$ ) (Table 1$)$.

All offspring produced were weighed and sexed at birth. Female offspring were cross-fostered to NPD periparturient lactating dams to produce litters of 12 LPD or NPD offspring per dam (LPD $n=36$ offspring; NPD $n=36$ offspring). The foster dams had always received NPD and continued to do so until weaning. This ensured that rats were only exposed to LPD in utero and that all rats received NPD from birth.

Following weaning, at 21 days, rats were housed 3 to 4 to a cage at $22 \pm 2{ }^{\circ} \mathrm{C}$ with a cycle of $12 \mathrm{~h}$ light (06:00-18:00 h), and free access to water and standard rat chow.
Table 1. Nutritional analysis of the two diets used in the study. The diets were isocaloric and the NPD had higher moisture content than LPD. The ratio of simple sugars to cornstarch in each diet was $2: 1$. The percent of fatty acids in each diet was: $27.9 \%$ saturated, $16.9 \%$ monounsaturates and $55.2 \%$ polyunsaturates.

\begin{tabular}{lcc}
\hline & \multicolumn{2}{c}{ Percentage of nutrients by weight } \\
\cline { 2 - 3 } & Low protein diet & Normal protein diet \\
\hline Crude protein & 6.0 & 18.0 \\
Carbohydrate & 75.0 & 59.1 \\
Crude oil & 6.0 & 2.6 \\
Crude fibre & 3.4 & 3.4 \\
Mineral mix & 5.5 & 5.5 \\
Methionine & 0.3 & 0.23 \\
Water & 3.8 & 11.17 \\
\hline
\end{tabular}

Procedures before diabetes study. Body weight was measured weekly between 10:00 $\mathrm{h}$ and 12:00 $\mathrm{h}$ and rats were placed in a metabolic cage for $24 \mathrm{~h}$ at weaning and at weeks 7 and 10 for estimation of fodder consumption and UAE. Systolic blood pressure (SBP) was estimated by an indirect tail cuff method at weeks 7 and 10 using the IITC Model 29 amplifier (Life Science Instruments, Calif., USA). Blood pressure data was analysed using Spike 2 software by a single observer (SEJ) who was blinded to the study groups.

Diabetes study. At 12 weeks 36 rats were selected at random for a one week diabetes study and allocated to either: Control (Cont) $n=6$ LPD, $n=6$ NPD; Diabetes (Diab) $n=6$ LPD, $n=6 \mathrm{NPD}$; or Diabetes plus insulin (D + I) $n=6$ LPD, $n=6$ NPD groups.

All rats were fasted overnight and tail vein glucose measured using a Medisense Meter and G2 test strips (Abbot Laboratories, Maidenhead, UK) before induction of diabetes. Both Diab and D + I rats received $50 \mathrm{mg} \cdot \mathrm{kg}^{-1}$ body weight streptozotocin intravenously to induce hyperglycaemia without ketosis. These rats had daily tail vein sampling for glucose estimation between 09: 00 and 10: $00 \mathrm{~h}$ and urinalysis for ketones using Ketostix (Bayer Diagnostics, Newbury, UK). The $\mathrm{D}+\mathrm{I}$ rats received a daily subcutaneous injection of Human Ultratard Insulin (NovoNordisk, Denmark) the quantity of which was titrated according to the blood glucose aiming for a peak glucose concentration, before insulin administration, of $15 \mathrm{mmol} \cdot \mathrm{l}^{-1}$, or more. A blood glucose concentration of $15 \mathrm{mmol} \cdot \mathrm{l}^{-1}$, or more, before administration of once daily protamine zinc insulin in streptozotocin rats equates to 'good control' and reflects much lower glucose concentrations throughout the day [22].

After administration of streptozotocin all rats were weighed daily and had SBP measured at 6 days in addition to estimation of UAE and fodder consumption.

Killing and perfusion fixation. At 13 weeks (after 7 days of diabetes) deep surgical anaesthesia was induced using a cocktail of $1 \mathrm{ml}$ Hypnorm $\left(0.315 \mathrm{mg}\right.$ fentanyl $\mathrm{ml}^{-1} ; 10 \mathrm{mg}$ fluanisone $\mathrm{ml}^{-1}$ (Janssen Pharmeutica, Beerse, Belgium) and $1 \mathrm{ml} \mathrm{mi-}$ dazolam $\left(5 \mathrm{mg} \cdot \mathrm{ml}^{-1}\right)$ diluted in $2 \mathrm{ml}$ water for injection, at a dose $0.27 \mathrm{ml} / 100 \mathrm{mg}$ body weight.

Total body perfusion fixation was done using phosphate buffered $4 \%$ formalin and $1 \%$ glutaraldehyde solutions (Sigma, Gillingham, UK). Each kidney was removed, stripped of its capsule and weighed separately using an electronic balance. The ratio of renal weight to body weight was calculated. The 
kidneys were stored in phosphate buffered $4 \%$ formalin solution at $4{ }^{\circ} \mathrm{C}$ before tissue preparation.

Tissue preparation. Either the right or left kidney from each rat was selected at random and cut into a minimum of ten slices of equal thickness, using a razor blade tissue fractionator [23] and alternate slices selected. After graded alcohol dehydration and infiltration with methacrylate (Technovite 7100, Hereus Kulzer, Wehrheim, Germany) the kidney slices were embedded in methacrylate resin. Each kidney block was sectioned exhaustively at $20 \mu \mathrm{m}$ intervals with a Universal Reichart Jung microtome. Every $10^{\text {th }}$ section and its adjacent section were selected to estimate the glomerular number using the fractionator technique [24]. This gave primary and secondary sampling fractions of $1 / 2$ and $1 / 10$ respectively. The points at which sampling was commenced for both the razor blade fractionator and sectioning were determined using a random number table. The slide pairs were stained with PAS and Mayers haematoxylin before examination.

Estimation of glomerular number. Using a method described [25] each slide pair was placed on the stages of two Olympus microscopes with a 100 Watt power source to produce adjacent images which were projected, using a mirror, at $159 \times$ magnification onto grids fastened to the table. One slide was moved systematically in $5.5 \mathrm{~mm}$ steps and the corresponding position found in the other slide. The presence of newly appearing glomeruli within the unbiased 2-dimensional counting frame was noted at each sampling point. The procedure was repeated until all the slide pairs for each kidney were sampled with an average of 110 glomeruli counted per kidney. The mean glomerular number per kidney and numerical density of glomeruli $(\mathrm{Nv})$ within the kidney were calculated. The coefficient of error for the technique was $4 \%$.

Estimation of glomerular volume. Ten slide pairs were selected at random and one slide from each pair examined using one of the above mentioned Olympus microscopes at the same magnification and sampling scheme. Using a point counting grid fastened to the table, the glomerular volume density $(V v)$ was estimated. Mean glomerular volume per kidney was calculated using the following formula:

Mean glomerular volume $=\frac{V_{v}}{N_{v}}$

[24].

Urinary albumin excretion rate ( $U A E)$. Volumes of $24 \mathrm{~h}$ urine were measured and aliquots were stored at $-40^{\circ} \mathrm{C}$ before estimating the urine albumin concentration by single-antibody radio-immunoassay with polyethylene glycol precipitation [26]. Rabbit anti-rat antibody RARa/Alb (Nordic Pharmaceuticals and Diagnostics, Tilberg, The Netherlands) and globulin-free rat serum (Sigma Chemical, St. Louis, Mo., USA) were used. The intra-assay and inter-assay coefficients of variation were less than $5 \%$ and less than $10 \%$, respectively.

Statistical analysis. All data were analysed using SPSS Version 7.5 for Windows 95.

Differences between two experimental groups were analysed using the Mann-Whitney U test. When more than two groups were compared, one-way analysis of variance (ANOVA) was used with the Bonferroni correction for multiple comparisons. Regression analysis was also done to determine the relative contribution of diet in utero, birth weight and systolic blood pressure to mean glomerular number. A $p$ value of less than 0.05 was considered to be statistically significant.
Table 2. Birth weight, body weights and systolic blood pressure in all 72 rats before induction of diabetes. All data are means \pm SD. Results were similar for the 36 rats randomly selected for the diabetes study. LPD, Low protein diet; NPD, Normal protein diet; SBP, systolic blood pressure

\begin{tabular}{lccc}
\hline & \multicolumn{2}{l}{ Study group } & \\
\cline { 2 - 4 } & LPD $(n=36)$ & NPD $(n=36)$ & $p$ value \\
\hline $\begin{array}{l}\text { Birth weight } \\
\text { (grams) }\end{array}$ & $5.4 \pm 0.5$ & $6.4 \pm 0.8$ & $<0.0001$ \\
$\begin{array}{l}\text { Weaning weight } \\
\text { (grams) }\end{array}$ & $50.8 \pm 3.8$ & $53.3 \pm 3.8$ & 0.011 \\
$\begin{array}{l}\text { Week 7 weight } \\
\text { (grams) }\end{array}$ & $169.4 \pm 14.2$ & $181.5 \pm 13.4$ & $<0.0001$ \\
$\begin{array}{l}\text { Week 10 weight } \\
\text { (grams) }\end{array}$ & $219.9 \pm 17.4$ & $250.5 \pm 17.4$ & $<0.0001$ \\
$\begin{array}{l}\text { SBP Week 7 } \\
\text { (mmHg) }\end{array}$ & $136 \pm 12$ & $127 \pm 10$ & 0.002 \\
$\begin{array}{l}\text { SBP Week 10 } \\
(\mathrm{mmHg})\end{array}$ & $137 \pm 9$ & $120 \pm 7$ & $<0.0001$ \\
\hline
\end{tabular}
ed.

All data are expressed as means \pm SD unless otherwise stat-

\section{Results}

Prior to diabetes. The conception rate of LPD rats was $90 \%$ of those that had vaginal plugging after a single overnight confinement with a male which is comparable to that seen in NPD rats. The LPD dams had slightly smaller litters than their NPD counterparts but this difference was not statistically significant (LPD $11 \pm 1.7$ pups vs NPD $13 \pm 1.5$ pups). Both LPD and NPD litters showed a normal distribution of birth weights within litters and a similar sex distribution.

The LPD rats were of lower birth weight (mean difference 1 gram less) compared to NPD rats (Table 2). Weight at weaning was also less and although the LPD rats increased their body weight with time they remained of lower body weight compared to NPD rats at all time points (Table 2). The LPD rats had higher SBP at weeks 7 and 10 (Table 2). Both LPD and NPD rats showed the expected increase in UAE with age and fodder consumption per unit body weight decreased with age. There was no significant difference in UAE or fodder consumption between the two groups (Table 3).

Renal size, glomerular number and volume. LPDCont rats had smaller kidneys than NPD-Cont rats $(0.925 \pm 0.009 \mathrm{~g}$ vs $1.200 \pm 0.173 \mathrm{~g}(p=0.041))$. Because LPD rats had lower body weight than NPD rats, the ratio of renal weight to body weight was calculated to correct for this. The renal weight to body weight ratio was also lower in the LPD rats: $0.770 \pm 0.002$ vs $0.902 \pm 0.111(p=0.009)($ Fig. 1$)$. 
Table 3. Urine albumin excretion (UAE) and fodder consumption in LPD and NPD rats. All data are median (range). Cont, control; Diab, diabetes group; D + I, Diabetes + Insulin group; $p$ values, Week 10 vs Diabetes Week; urine albumin excretion, LPD ${ }^{a} p=0.043$ NPD, ${ }^{c} p=0.028$; fodder consumption LPD ${ }^{\mathrm{b}} p=0.028,{ }^{\mathrm{d}} p=0.046$. There was no significant difference between LPD and NPD rats at any time point

\begin{tabular}{|c|c|c|c|c|c|}
\hline & & \multicolumn{2}{|l|}{ UAE (mg/24 h) } & \multicolumn{2}{|c|}{ Fodder consumption (mg/g body weight/24 h) } \\
\hline & & Week 10 & Diabetes & Week 10 & Diabetes \\
\hline LPD & $\begin{array}{l}\text { Cont } \\
\text { Diab } \\
\text { D + I }\end{array}$ & $\begin{array}{l}0.450(0.24-0.93) \\
0.400(0.29-1.11) \\
0.460(0.36-2.45)\end{array}$ & $\begin{array}{l}0.322(0.17-0.57) \\
0.765^{\text {a }}(0.27-1.44) \\
0.489(0.26-2.10)\end{array}$ & $\begin{array}{l}0.101(0.09-0.11) \\
0.102(0.06-0.13) \\
0.104(0.01-0.14)\end{array}$ & $\begin{array}{l}0.095(0.08-0.10) \\
0.182^{\mathrm{c}}(0.11-0.29) \\
0.104(0.08-0.14)\end{array}$ \\
\hline NPD & $\begin{array}{l}\text { Cont } \\
\text { Diab } \\
\text { D + I }\end{array}$ & $\begin{array}{l}0.615(0.38-2.20) \\
0.540(0.20-0.80) \\
0.450(0.31-0.91)\end{array}$ & $\begin{array}{l}0.458(0.31-0.48) \\
0.680^{\mathrm{b}}(0.07-1.04) \\
0.597(0.11-1.30)\end{array}$ & $\begin{array}{l}0.113(0.10-0.15) \\
0.107(0.10-0.11) \\
0.010(0.05-0.14)\end{array}$ & $\begin{array}{l}0.059(0.05-0.10) \\
0.141^{\mathrm{d}}(0.02-0.21) \\
0.118(0.09-0.14)\end{array}$ \\
\hline
\end{tabular}

The LPD rats also had a biologically significant reduction in mean glomerular number $(17435 \pm 2074$ vs $24846 \pm 1864, p<0.0001)$. Within study groups there was no linear relation between birth weight and mean glomerular number (Fig. 2). A crude estimate of glomerular density, and number of glomeruli per milligram kidney weight, confirmed the significant reduction in glomeruli in LPD rats $\left(16.4 \cdot 10^{3} \pm 2.8\right.$ vs $\left.21.0 \times 10^{3} \pm 3.2, p<0.0001\right)$.

Multiple regression analysis demonstrated that diet in utero was a strong determinant of glomerular number (standardised $\beta=0.769, p<0.0001$ ) rather than systolic blood pressure (standardised $\beta=-0.45$, $p=0.756$ ) or birth weight (standardised $\beta=0.132$, $p=0.207)$.

There was no significant difference in mean glomerular volume between LPD-Cont and NPD-Cont rats $\left(1.105 \pm 0.148 \cdot 10^{6}{\mu \mathrm{m}^{3}}^{3}\right.$ vs $1.078 \pm 0.167 \cdot 10^{6}$ $\mu \mathrm{m}^{3} p=\mathrm{NS}$ ) (Fig. 1).

Diabetes study. The sample of LPD $(n=18)$ and NPD rats $(n=18)$ selected were representative of their respective groups with similar birth weight, body weight, SBP, UAE and fodder consumption to the population as a whole.

Blood Glucose concentrations (Fig. 3). Before induction of diabetes, fasting glucose concentrations were similar between LPD and NPD rats. After administration of streptozotocin, blood glucose concentrations increased to a similar daily value in LPD-Diab and NPD-Diab rats, with a mean overall glucose of $22.5 \pm 1.8 \mathrm{mmol} \cdot \mathrm{l}^{-1} \quad$ vs $23.1 \pm 2.1 \mathrm{mmol} \cdot \mathrm{l}^{-1}$ $(p=\mathrm{NS})$ and no rat developed ketonuria.

In the LPD-D + I and NPD-D + I rats blood glucose increased to a concentration greater than $18 \mathrm{mmol} \cdot \mathrm{l}^{-1}$ within $48 \mathrm{~h}$ of administration of streptozotocin. Insulin treatment started once blood glucose had risen to this value. Thereafter glucose concentrations were significantly lower than in both the LPDDiab and NPD-Diab group. The mean overall glucose concentrations in LPD-D + I and NPD-D + I rats were $14.2 \pm 3.4 \mathrm{mmol} \cdot \mathrm{l}^{-1}$ vs $11.2 \pm 1.8 \mathrm{mmol} \cdot \mathrm{l}^{-1}$ $(p=\mathrm{NS})$ and the only significant difference in daily glucose was at day $6 \quad\left(14.6 \pm 2.7 \mathrm{mmol} \cdot \mathrm{l}^{-1}\right.$ vs $\left.8.2 \pm 3.9 \mathrm{mmol} \cdot 1^{-1} p=0.007\right)$. The mean insulin dosages in LPD-D + I and NPD-D + I rats were $21 \pm 2$ (range 17-23) vs $19 \pm 3$ (range 14-24) units a day, $p=\mathrm{NS}$.

Body weight (Fig. 3). Body weight continued to increase in LPD-Cont and NPD-Cont rats, although the weight of LPD-Cont rats was consistently lower than NPD-Cont rats.

After administration of streptozotocin all diabetic rats lost approximately $15 \%$ of their body weight compared to pre-diabetic values by day 2 . Thereafter body weight in LPD-Diab and NPD-Diab rats stabilised and increased slightly but they remained 10 to $15 \%$ lighter than their respective controls. Both LPD-D + I and NPD-D + I rats began to regain body weight with insulin and, by day 5 they had similar body weight to their respective controls. The proportional decrease in body weight was similar between LPD-Diab and NPD-Diab rats.

Fodder consumption. All rats showed a decrease in fodder consumption per unit body weight with age before diabetes. Both LPD-Diab and NPD-Diab rats had an increase in fodder consumption compared to their pre-diabetic values. There was, however, no significant difference in the rates of fodder consumption between LPD-Diab and NPD-Diab rats (Table 3).

Systolic blood pressure. Systolic blood pressure was not significantly changed a week after the induction of diabetes in both LPD and NPD rats. SBP remained higher in LPD rats compared to NPD rats $(138 \pm 5 \mathrm{mmHg}$ vs $127 \pm 7 \mathrm{mmHg}, p<0.0001)$.

Urine albumin excretion. There was no significant difference in UAE between the two groups before diabetes despite the marked reduction in glomerular number in LPD rats. Both LPD-Diab and NPDDiab had the expected increase in UAE in response to diabetes but there was no significant difference between these two groups (Table 3). 

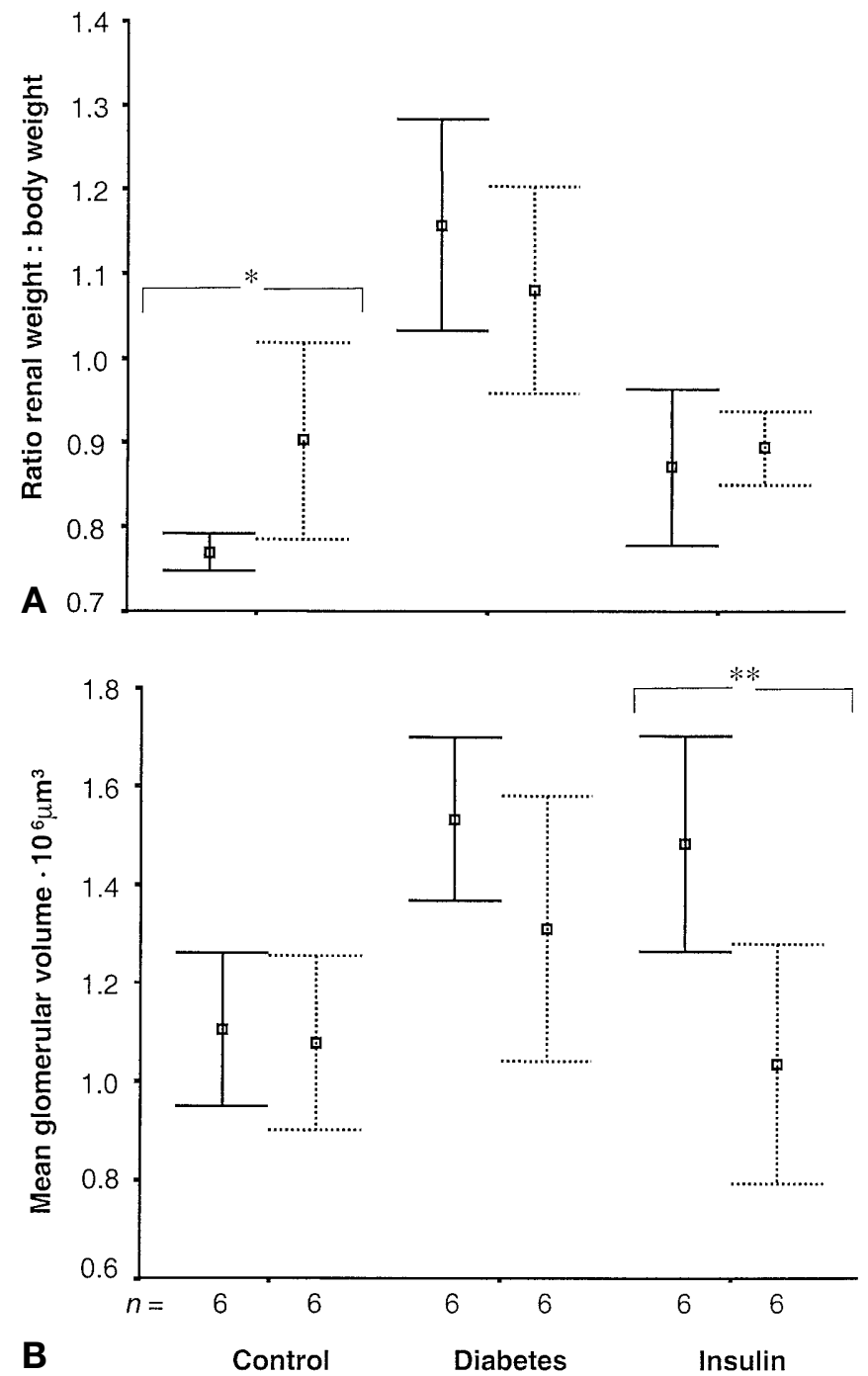

Fig. 1(A, B). Error bar plots of renal size (A) and glomerular volume (B) in low protein diet (LPD) (solid lines) and normal protein diet (NPD) (dotted lines) Error bars $=95 \%$ confidence intervals. * LPD-Control vs NPD-Control $p=0.009$ ** LPD-Diabetes \pm Insulin vs NPD-Diabetes + Insulin $p=0.015$. The proportional increase in renal size from control to diabetic rats was significantly higher in LPD rats vs NPD rats $50 \pm 12 \%$ vs $20 \pm 4 \%(p=0.003)$. The proportional increase in glomerular volume from control to diabetic rats was significantly higher in LPD rats vs NPD rats $40 \pm 17 \%$ vs $20 \pm 6 \%(p=0.03)$

Renal size (Fig. 1). Renal size was significantly increased in LPD-Diab rats seven days after administration of streptozotocin as determined by both renal weight [LPD-Cont $0.925 \pm 0.009 \mathrm{~g}$ vs LPD-Diab $1.270 \pm 0.230 \mathrm{~g}(p=0.003)]$ and the ratio of renal weight to body weight $[0.770 \pm 0.002$ vs $1.157 \pm 0.120$ $(p<0.0001)]$. A similar trend was seen in NPD rats with an increase in both renal weight [NPD-Cont $1.200 \pm 0.173 \mathrm{~g}$ vs NPD-Diab $1.287 \pm 0.183 \mathrm{~g} \quad(p=$ $0.003)]$ and in the ratio of renal weight: body weight $[0.902 \pm 0.111$ vs $1.080 \pm 0.116(p<0.001)]$.

There was no significant difference in absolute renal size between LPD-Diab and NPD-Diab rats. Be-

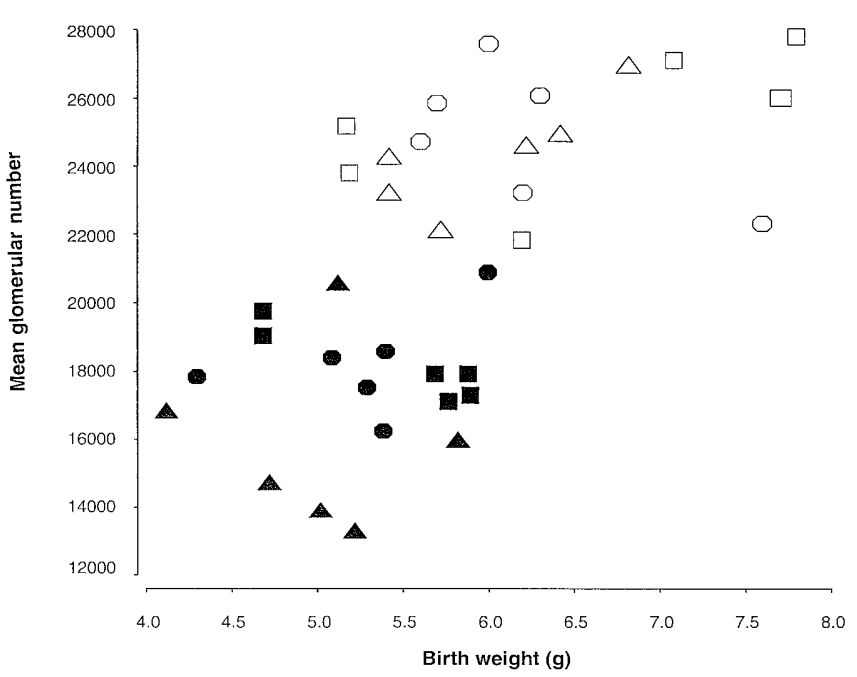

Fig. 2. Scatter plot of mean glomerular number and birth weight in low protein diet rats (solid symbols) and normal protein diet rats (open symbols). control groups (Triangles); insulin groups (Circles); Diabetes \pm Insulin group (Squares)

cause LPD rats had smaller kidneys than NPD rats before induction of diabetes the proportional increase in renal size relative to controls was determined in LPD and NPD rats. The LPD-Diab rats exhibited a greater proportional increase in renal size 1 week after administration of streptozotocin compared to NPD rats [ $\Delta$ diabetes: control $50 \pm 12 \%$ (LPD) vs $20 \pm 4 \%$ (NPD) $p=0.003]$.

In both LPD-D + I and NPD-D + I rats, renal enlargement was prevented by insulin treatment, renal size in both these groups being similar between controls and $\mathrm{D}+\mathrm{I}$ rats (ratio renal weight to body weight Cont vs $\mathrm{D}+\mathrm{I}$ : $\mathrm{LPD}$ rats $=0.770 \pm 0.002$ vs $0.870 \pm 0.009 p=\mathrm{NS} ; \mathrm{NPD}$ rats $=0.902 \pm 0.111$ vs $0.893 \pm 0.004 p=\mathrm{NS})$.

Glomerular number. Overall LPD rats had a biologically significant reduction in mean glomerular number $(17435 \pm 2074$ vs $24846 \pm 1864, \quad p<0.0001)$ (Fig. 2). There was no significant difference in glomerular number between the subgroups within the LPD and NPD rats.

Glomerular volume (Fig. 1). There was no significant difference in mean glomerular volume between LPD-Cont and NPD-Cont ( $p=$ NS). Glomerular volume was increased in both LPD-Diab and NPDDiab rats compared to their respective controls: $\left(\mathrm{LPD}\right.$ rats $=1.105 \pm 0.148 \cdot 10^{6} \mu \mathrm{m}^{3}$ vs $1.533 \pm 0.159$. $10^{6} \mu \mathrm{m}^{3}, p=0.003$; NPD rats $=1.078 \pm 0.167 \cdot 10^{6} \mu \mathrm{m}^{3}$ vs $\left.1.310 \pm 0.257 \cdot 10^{6} \mu \mathrm{m}^{3}, p=0.003\right)$. Although there was no significant difference in mean glomerular volume between LPD-Diab and NPD-Diab rats the LPD-Diab rats exhibited a greater proportional increase in glomerular volume ( $\Delta$ diabetes: control $40 \pm 17 \%$ vs $20 \pm 6 \%, p=0.03)$. 

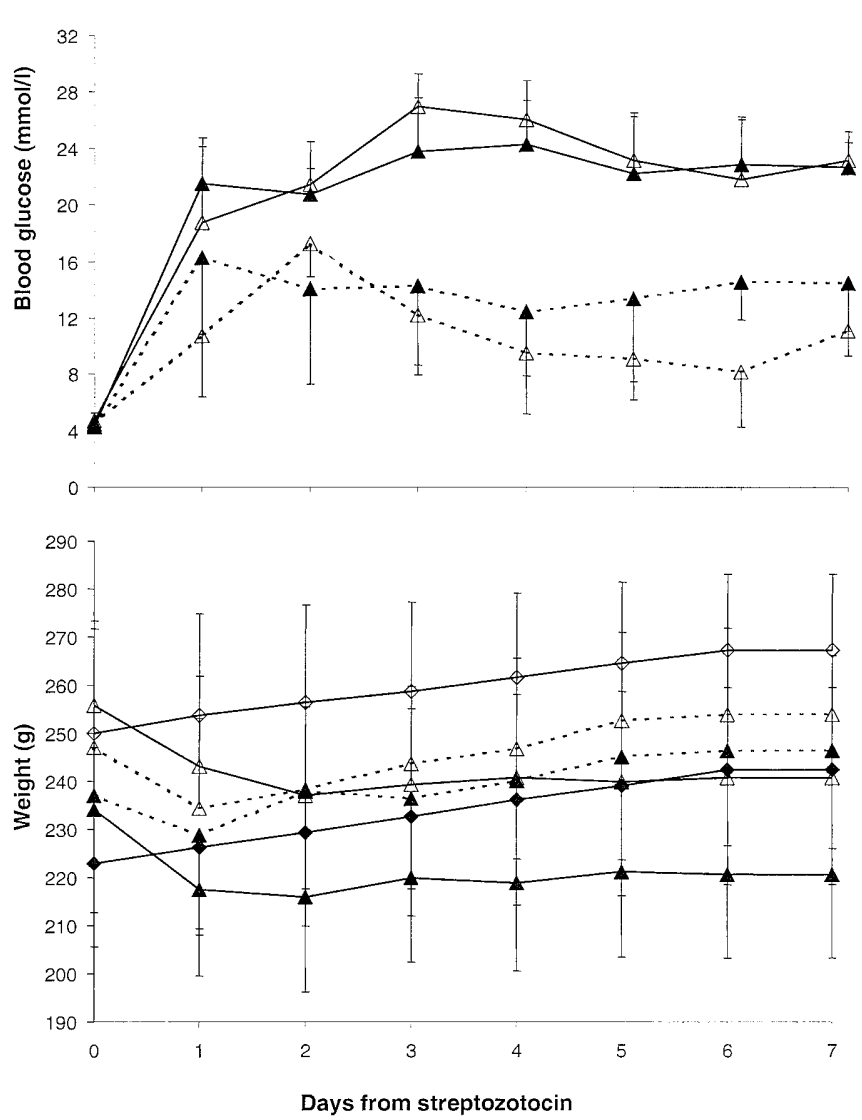

Fig.3(A, B). Serial blood glucose (A) and body weight (B) post induction of diabetes in low protein diet (LPD) and normal protein diet (NPD) rats. SD, error bars. Subgroups: Control (Cont), Diabetes (Diab), Diabetes + Insulin (D+I). LPD-Cont $\prec$ NPD-Cont $\prec$ LPD-Diab $\_$NPD-Diab

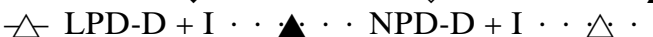

Administration of insulin prevented glomerular hypertrophy in NPD-D + I rats but not in LPD$\mathrm{D}+\mathrm{I}$ rats (Cont vs $\mathrm{D}+\mathrm{I}$ : $\mathrm{LPD}$ rats $=1.105 \pm$ $0.148 \cdot 10^{6} \mu \mathrm{m}^{3}$ vs $1.484 \pm 0.209 \cdot 10^{6} \mu \mathrm{m}^{3}, \quad p=0.001$, $\mathrm{NPD}$ rats $=1.078 \pm 0.167 \cdot 10^{6} \mu \mathrm{m}^{3}$ vs $1.035 \pm 0.232$. $\left.10^{6} \mu \mathrm{m}^{3}, p=\mathrm{NS}\right)$. This finding contrasts with the effect on renal hypertrophy.

\section{Discussion}

Our study specifically examines the combined effects of intra-uterine LPD and experimental diabetes. Administration of $6 \%$ protein but isocaloric diet resulted in rats with a birth weight approximately 1 gram (16\%) lower than offspring of dams fed $18 \%$ protein (NPD) throughout pregnancy. These LBW rats did not exhibit "catch-up" growth, weight at weaning and adult weight remaining less than NPD rats.

The LPD rats had a statistically significant reduction in glomerular number with similar glomerular volume but an augmented acute renal response to diabetes compared to NPD rats.
Other groups, using an isocaloric LPD from day 1 of pregnancy to delivery have shown that LPD produces LBW rats [21, 27-30]. Exposure to LPD in utero also results in reduction in the following parameters: adult body weight [17], renal size [15, 27] and glomerular number $[15,20,21]$. Glomerular number has been shown to be reduced using either $5 \%$ LPD from day 8 to 21 gestation [15], 6\% LPD for the whole gestation period [21] or $9 \%$ LPD for the whole gestation period [20]. The $6 \%$ LPD model used in this study is not a model of energy malnutrition. All dams only received an isocaloric LPD for one week before mating and for the duration of pregnancy. Thus, the duration of LPD administration was shorter than some other models that have used long-term dietary restriction which is associated with reduced rates of pregnancy and increased fetal and early neonatal loss [16-18].

The administration of LPD both in utero and postnatally until weaning influences the severity of hypertension in adulthood [31]. This study was designed specifically to examine the effects of intra-uterine nutrition on glomerular number and development of hypertension independent of post-natal programming; therefore the LPD was not continued post-natally.

In order to make the LPD isocaloric to NPD it was necessary to increase both the crude oil and carbohydrate content of the diet. Offspring of dams fed a diet with a very high ratio of saturated to unsaturated fatty acids, without protein restriction, have been shown to have hypertension post-natally [32]. In our study, however, whilst the total amount of crude oil in the LPD was twice that in the NPD the saturated to unsaturated fatty acids ratio was the same in both diets. Similarly the ratio of sucrose to cornstarch was the same in both diets. Although we cannot exclude the possibility that increasing both the proportion of carbohydrate and crude oil content in the diet had an independent effect on fetal programming this does not seem likely as both the ratios of fatty acids and sucrose to cornstarch were the same between the two diets.

Systolic blood pressure. Epidemiological studies suggest that the combination of LBW and adulthood obesity predisposes the development of hypertension in adulthood [3]. The LPD rats had high systolic blood pressure in absence of adult obesity which concurs with previous studies using LPD of differing severities [19,33].

In addition to high systolic blood pressure, LPD rats had smaller kidneys with reduced mean glomerular number but similar mean glomerular volume to NPD rats. Whether high systolic blood pressure arises because of reduced glomerular number or vice versa is not known $[4,5]$. Although systolic blood pressure was negatively correlated with mean glomerular number, multiple regression analysis showed that LPD itself had a greater influence on mean glomeru- 
lar number than systolic blood pressure. Thus, it could be speculated that the reduced glomerular number induced by LPD subsequently determines systolic blood pressure.

The observation that mean glomerular volume was not increased despite high systolic blood pressure is interesting. This suggests that either the glomeruli are not able to compensate for the high systolic blood pressure or that the magnitude of blood pressure rise is not sufficient to influence glomerular volume.

Response to diabetes. The LPD rats and NPD rats developed renal and glomerular enlargement in response to diabetes but LPD rats had a greater proportional increase in renal size and glomerular volume compared to NPD rats.

As expected, insulin treatment prevented the increase in renal size and glomerular volume with diabetes in NPD rats. In the LPD animals, although renal size was normalised with insulin treatment, glomerular volume remained high. Thus, abnormal intrauterine nutrition seems to influence the acute renal response to diabetes and to insulin treatment.

Effect of intra-uterine LPD on glomerular hypertrophy with diabetes. The exact mechanisms by which glomerular hypertrophy occurs with diabetes are not known. It is likely that glomerular hypertrophy results from a combination of increase in capillary length and mesangial volume. Despite having reduced glomerular number the LPD rats did not increase their glomerular volume to compensate for any possible reduction in filtration surface area.

Our results suggest LPD rats retain the ability to enlarge their glomeruli in response to post-natal insults, such as diabetes and indeed do so in an exaggerated fashion. Despite normalisation of body weight and renal size with insulin treatment LPD rats had persistently increased glomerular volume. This suggests that exposure to isocaloric LPD in utero not only leads to a reduction in glomerular number but also to failure of glomerular volume regulation and abnormal adaptation to hyperglycaemia and insulin. Thus it seems that LPD in utero has a greater influence on the regulation of glomerular hypertrophy than that observed on renal hypertrophy.

Although mean blood glucose for the duration of diabetes was similar in LPD-D + I and NPD-D + I groups, blood glucose on day 6 was higher in the LPD-D + I group. This is unlikely to account for the difference in glomerular volume, given that body weight and renal size were similar in the two groups. At most, it suggests that glomerular volume might be more sensitive to changes in blood glucose than body weight and overall renal size.

Urine albumin excretion. The LPD rats had significantly fewer glomeruli per kidney, compared to
NPD rats, but the two groups had similar UAE. This could imply that the filtration rate per glomerulus was higher in LPD rats. An increase in filtration rate per glomerulus that predates the development of diabetes could explain the greater proportional increase in glomerular volume and failure to reverse glomerular hypertrophy with insulin in rats exposed to LPD in utero.

Implications of study findings. These findings, together with the observation that LBW rats have fewer glomeruli, tends to support the hypothesis that intrauterine malnutrition could programme renal responses to adult disease such as diabetes.

The presence of high SBP before diabetes in LPD rats and the fact that insulin therapy did not reverse glomerular hypertrophy induced by diabetes is of interest.

Acknowledgements. Dr S. E. Jones was funded by a Northern and Yorkshire NHS Executive Research Training Fellowship and the blood pressure equipment was funded by the British Diabetic Association. We are grateful to $\mathrm{Mr} \mathrm{R}$ Stewart and his technicians in the Comparative Biology Centre Newcastle upon Tyne for their excellent animal husbandry and to Mrs K Nyborg in Department M, Aarhus University Hospital, for estimating the urine albumin.

\section{References}

1. Hales C, Barker D, Hales C, Fall C, Osmond C, Clark P (1993) Fetal growth and impaired glucose tolerance in men and women. Diabetologia 36: 225-228

2. Barker D, Hales C, Fall C, Osmond C, Phipps K, Clark P (1993) Type II (non-insulin dependent) diabetes mellitus, hypertension and hyperlipidaemia (syndrome $\mathrm{X}$ ): relation to reduced fetal growth. Diabetologia 36: 62-67

3. Barker D, Bull A, Osmond C, Simmonds S (1990) Fetal and placental size and risk of hypertension in adult life. BMJ 302: 259-262

4. Brenner B, Garcia D, Anderson S (1988) Glomeruli and blood pressure: less of one and more of the other? Am J Hyperten 1: 335-347

5. Brenner B, Chertow G (1994) Congentital oligonephropathy and the etiology of adult hypertension and progressive renal injury. Am J Kidney Dis 23: 171-175

6. Christiansen J, Gammelgaard J, Frandsen M, Parving H-H (1981) Increased kidney size, glomerular filtration rate and renal plasma flow in short term insulin dependent diabetics. Diabetologia 20: 451-456

7. Østerby R, Parving H-H, Hommel E, Jorgensen H, Lokkegaard H (1990) Glomerular structure and function in diabetic glomerulopathy. Early to advanced stages. Diabetes 39: 1057-1063

8. Baumgartl H, Banholzer P, Sigl G, Haslbeck M, Standl E (1998) On the prognosis of IDDM patients with large kidneys. The role of large kidneys for the development of diabetic nephropathy. Nephrol Dial Transplant 13: 630-634

9. Seyer-Hansen K (1978) Renal hypertrophy in experimental diabetes: A comparison to compensatory hypertrophy. Diabetologia 14: 325-328 
10. Seyer-Hansen K, Hansen J, Gundersen H (1980) Renal hypertrophy in experimental diabetes. A morphometric study. Diabetologia 18: 501-505

11. Seyer-Hansen K (1983) Renal hypertrophy in experimental diabetes. Kidney Int 23: 643-646

12. Rossing P, Tarnow L, Nielsen F, Hansen B, Brenner B, Parving H-H (1995) Low birth weight - a risk factor for development of diabetic nephropathy? Diabetes 44: 1405-1407

13. Bendtsen T, Nyengaard J (1992) The number of glomeruli in Type I (insulin dependent) and Type II (non-insulin dependent) diabetic patients. Diabetologia 35: 844-850

14. Gilbert T, Lelièvre-Pérgorier M, Merlet-Bénichou C (1990) Immediate and long-term renal effects of fetal exposure to gentamicin. Pediat Nephrol 8: 175-180

15. Merlet-Bénichou C, Gilbert T, Muffat-Joly M, LelièrvrePérgorier M, Leroy B (1994) Intrauterine growth retardation leads to a permanent nephron deficit in the rat. Pediat Nephrol 8: 175-180

16. Stewart R, Sheppard H (1971) Protein-calorie deficiency in rats. Growth and reproduction. Br J Nutr 25: 175-181

17. Turner M (1973) Perinatal mortality, growth and survival to weaning in offspring of rats reared on diets moderately deficient in protein. Br J Nutr 29: 139-147

18. Widdowson E, Cowen J (1972) The effect of protein deficiency and calorie deficiency on the reproduction of rats. Br J Nutr 27: 85-95

19. Langley-Evans S, Welham S, Sherman R, Jackson A (1996) Weanling rats exposed to maternal low-protein diets during discrete periods of gestation exhibit differing severity of hypertension. Clin Sci (Colch) 91: 607-615

20. Langley-Evans S, Welham S, Jackson A (1999) Fetal exposure to low protein diet impairs nephrogenesis and promotes hypertension in the rat. Life Sciences 64: 965-974

21. Mackenzie H, Luyckx V, Lawler E, Troy J, Brenner B, Nyengaard J (1998) Reduced glomerular number in the offspring of female rats subjected to gestational dietary protein restriction: a quantitation using unbiased stereological techniques. J Am Soc Nephrol 9: 616a
22. Rasch R (1979) Control of blood glucose concentrations in the streptozotocin diabetic rat using long-acting heat-treated insulin. Diabetologia 16: 185-190

23. Baddeley A, Gundersen H, Cruz-Orive L (1986) Estimation of surface area from vertical sections. J Microsc 142: 259-276

24. Gundersen H (1986) Stereology of arbitrary particles: a review of unbiased number and size estimators and the presentation of some new ones, in memory of William R. Thompson. J Microsc 143: 3-45

25. Nyengaard J, Bendtsen T (1990) A practical method to count the number of glomeruli in the kidney as exemplified in various animal species. Acta Stereologica 9: 243-258

26. Flyvbjerg A, Marshall S, Frystyk J, Hansen K, Harris A, Ørskov H (1992) Octreotide administration in diabetic rats: effects on renal hypertrophy and urine albumin excretion. Kidney Int 41: 805-812

27. Goldstein R, Hook J, Bond J (1979) The effects of maternal protein deprivation on renal development and function in neonatal rats. J Nutr 109: 949-957

28. Pond W, Wu J (1981) Mature body weight and life span of male and female progeny of primiparous rats fed a low protein or adequate diet throughout pregnancy. J Nutr 111: 1949-1954

29. Langley-Evans S, Gardner D, Jackson A (1996) Maternal protein restriction influences the programming of the rat hypothalamic pituitary adrenal axis. J Nutr 126: 1578-1585

30. Langley-Evans S, Gardner D, Jackson A (1996) Protein intake in pregnancy, placental glucocorticoid metabolism and the programming of hypertension in the rat. Placenta 17: 169-172

31. Petry C, Ozanne S, Wang C, Hales C (1996) Early protein restriction and obesity independently induce hypertension in year old rats. Clin Sci (Colch) 93: 147-152

32. Langley-Evans S, Calmp A, Grimble R, Jackson A (1996) Influence of dietary fats upon systolic blood pressure in the rat. Int J Food Sci Nutr 47: 417-425

33. Langley-Evans S, Jackson A (1994) Increased systolic blood pressure in adult rats induced by fetal exposure to maternal low protein diet. Clin Sci (Colch) 86: 217 